\title{
Os sujeitos e os sentidos: o caso de alunos de engenharia
}

\author{
Raquel Ribeiro Moreiral \\ Vejane Gaelzer ${ }^{2}$
}

Résumé: Le travail suivant cherche analyser la production de sens sur la violence contre les enfants à partir des textes académiques des élèves d'engénieries, aynt comme base téorique l'Analyse du Discours française. Pour elle, l'appréhension des sens a lieu à partir d'un geste d'interprétation. Selon Orlandi (1997), ce geste découle dans lieu d'histoire et de la societé et a une direction siblée, qui est nomée politique. Ainsi, il est toujours possible d'appréhender la textualisation de polítique dans le geste d'interprétation. Aynt pour parameter telle conception, nous partons d'un écrit jornalistique sur la relation entre l'abus enfantil et l'aliénation parentale. Cette dernière a servi de base pour une production textuelle (notre corpus d'analyse), à partir de laquelle il a été necéssaire discuter la tematique abordée, relationant les données du texte travaillé avec les effets des sens produits par les élèves. Notre objective est de chercher les modes de symbolization effectués par les universitaires par rapport à la triade: pères, mères et enfants, et leus relations possible d'abus et de violence. Pour cela, nous ferons une analyse qualitative, basée sur les dispositifs théoriques et méthodologiques de l'analyse du discours. Nous observerons que ces sujets, même s'ils ont des univers sociaux et idéologiques différents, tendent à adhérer à um ordre plus conservateur. Ils renforcent aussi, presque toujours, une perspective individualiste et méritocratique, fondée sur la hierarchie et la juste récompense des relations sociales. Dans le cas particulier que nous analysons, les textes des étudiants mettent en évidence des effets conservateurs qui, dans des cas plus extremes, tentent de mantenir le status quo, en plus de renforcer les divisions sociales e idéologique poursuivies par les défenseurs de ce discours dans d'autres aspects sócio-discursifs.

Mots-clés: production de sens; politique; élèves d'ingénieries.

Resumo: O presente trabalho procura analisar a produção de sentidos a respeito da violência contra crianças em textos acadêmicos de alunos de engenharias, tendo como pressuposto teórico a Análise de Discurso francesa. Para a AD, a "apreensão" dos sentidos acontece a partir de um gesto de interpretação. Segundo Orlandi (1997), esse gesto se dá sempre de algum lugar da história e da sociedade e tem uma direção, que é o que chamamos de política. Desse modo, sempre é possível apreender a textualização do político no gesto de interpretação. Tendo com parâmetro tal concepção, partimos de uma matéria jornalística sobre a relação abuso infantil/alienação parental, que serviu como base para uma produção textual (nosso corpus de análise), na qual era necessário discutir a temática abordada, relacionando os dados do texto trabalhado com os efeitos de sentido pelos alunos produzidos. Nosso

1 Professora Doutora da Universidade Tecnológica Federal do Paraná (UTFPR).

2 Professora Doutora do Instituto Federal Farroupilha (IFAR). 
objetivo é investigar os modos de simbolização feitos pelos acadêmicos em relação à tríade: pais, mães e filhos, e suas possíveis relações de abuso e violência. Para tanto, trabalharemos em uma análise qualitativa, a partir de dispositivos teóricos e metodológicos da Análise de Discurso. Observamos que esses sujeitos, mesmo oriundos de universos sociais e ideológicos diversos, costumam inscrever-se em uma ordem política mais conservadora, reforçando, quase sempre, uma perspectiva individualista e meritocrática, baseada na hierarquização e devida premiação das relações sociais. No caso específico que estamos analisando, seus textos apontam para efeitos de sentido conservadores que, em casos mais extremos, tentam manter o status quo, reforçando as divisas sociais e ideológicas perseguidas pelos seus defensores em outros aspectos sócio-discursivos.

Palavras-chave: produção de sentidos; político; alunos de engenharias.

\section{Introdução}

Trabalhar linguagem e produção de textos em cursos de engenharia não é uma tarefa fácil. Em primeiro lugar, porque disciplinas que compreendam o universo da linguagem têm normalmente um caráter instrumental e, além disso, entram em discordância com as preferências dos alunos. Não é difícil ouvirmos: "sou péssimo em português, por isso escolhi engenharia", "faço engenharia justamente para fugir de produção de textos" e etc... Ainda assim, na prática de sala de aula, esses alunos apresentam os mesmos problemas de quase todos os alunos que ingressam no ensino superior hoje em dia, em termos textuais, mas, muitas vezes, devido à concorrência dos cursos, um domínio um pouco maior das estruturas linguísticas em relação a alunos de licenciaturas, por exemplo.

Contudo, é em relação à produção dos sentidos que observamos uma diferença um pouco maior entre, por exemplo, as duas áreas acima citadas. De um modo geral, os jovens, hoje, não possuem, como há 15 ou 20 anos, uma "verve quixotesca", quer dizer, aquele espírito contestador, mais tolerante e que luta por mudanças socioeconômicas não faz mais parte das universidades como antes. O jovem que frequenta nossas salas de aulas é mais introspectivo, mais voltado para seus interesses individuais e pouco ousa reivindicar mudanças. Se o faz, dificilmente é com o objetivo de que extrapole os círculos que frequenta.

$\mathrm{Se}$, todavia, essa é uma característica que observamos na totalidade, quando nos referimos às diferenças na produção dos sentidos dos alunos de engenharias, aludimos a posicionamentos que, mesmo que ecoem em outros grupos, nem sempre aparecem tão abertamente defendidos como entre os sujeitos desta nossa pesquisa. Entendemos que o sentido de algo não existe em si mesmo, acoplado à materialidade linguística, mas só pode ser constituído em referência às condições de produção de um determinado enunciado, portanto ele é múltiplo e movente, pois só se produz dentro de determinações histórico-sociais. Assim, o que para muitos alunos pode ser visto como desrespeito, para outros não passa da defesa de direitos.

É claro que não estamos generalizando, mas há pontos encontrados mais abundantemente em textos e discussões de alunos de engenharias que nos orientam a entendê-los como produtores/reprodutores de um discurso mais conservador ${ }^{3}$.

3 Trazemos um exemplo (além das análises que compõem o trabalho) para ilustrar: ao se discutir um texto sobre o Programa Mais Médicos, escrito por um médico e vereador de Porto Alegre, observamos, em dado momento, que o autor afirmava que o programa era ruim porque aumentaria os atendimentos iniciais em $60 \%$, 
Isto é, em diversos momentos a discussão estritamente textual sobre o modo como os argumentos trazidos construíam determinados efeitos de sentido não propiciava reconhecimento de equívocos - equívocos textuais, mas também discursivos - mas tornava-se estopim para marcar um autoposicionamento frente à questão (não importa o que o texto diz, eu penso assim!). E visões similares foram encontradas em discussões sobre diminuição da menoridade penal, propriedade privada, relações de gênero e etc... Sempre em consonância com uma visão mais centrada no indivíduo e na defesa de seus direitos particulares.

Portanto, quando delimitamos os efeitos de sentido produzidos por alunos de engenharias, estamos constituindo-os - os efeitos - a partir dessa relação - mais defensora das individualidades - desses sujeitos com a(s) formação(ões) ideológica(s) que os determinam. É nesse imbricamento do um - sentido - com o outro - sujeito (lembrando que os sujeitos só existem a partir da interpelação ideológica) - que os discursos ganham forma e pertencimento, constituindo, por exemplo na universidade, os falares dos alunos das engenharias e os falares dos alunos das licenciaturas. Pêcheux (1996, p. 149) afirma que:

[...] todo o meu trabalho encontra sua definição aqui, nesse vínculo da questão da constituição do sentido com a da constituição do sujeito, um vínculo que não é marginal (como, por exemplo, o caso especial dos "rituais" ideológicos de ler e escrever), mas que se situa dentro da própria "tese central", na figura da interpelação.

Nesse sentido, sujeitos - alunos de engenharias - e sentido constituem um certo tipo de discurso que, não acidentalmente, sustenta um cenário mais autocentrado nos indivíduos, com a condição do político travestida de opiniões moralizantes e conservadoras. E dizemos isso porque entendemos que é a língua o espaço em que tais condições materializam-se, e é nela que, especialmente no uso mais abundante dos adjetivos de qualidades e das sentenças declarativas, por exemplo, podemos fundamentar o vínculo entre a constituição desses sujeitos e a produção dos sentidos que ora nos chamam a atenção.

\section{Sujeito e Língua}

Ao tratarmos da interpelação-identificação do sujeito, é pertinente destacar que trabalhamos com a materialidade de língua que se dá nas e a partir das práticas sociais e, assim, sentidos são constituídos, silenciados e/ou excluídos. Para Pêcheux (1997), a língua é percebida como base sobre a qual os processos discursivos são desenvolvidos. Isso significa que o funcionamento da língua não é apenas linguístico, mas dela participam os elementos de produção do discurso. A relação da língua com a exterioridade, com o sujeito não é uma questão aleatória, antes uma necessidade, porque ela precisa da fronteira externa para significar e é afetada pela exterioridade, pelas questões históricas e por efeitos sentidos não controláveis. De acordo com o autor, a língua não é transparente e deve ser vista em seu funcionamento; nessa perspectiva, a falha, a contradição, o equívoco, a incompletude são constitutivos da língua e constituem o seu real, afetado pelo simbólico. Assim, o real da língua é aquilo que não pode ser expresso pelo sistema da língua, mas apreendido pela língua em funcionamento. Neste viés, os sentidos não são dados simplesmente pelos signos

assim mais pessoas descobririam estar doentes, o que aumentaria as filas para exames especializados e cirurgias. Independentemente do posicionamento em relação ao Programa, muitos alunos não conseguiam enxergar, nessa explicação, justificativa que validasse a argumentação do autor. Todavia, em turmas de engenharias, o discurso que apareceu com mais recorrência foi: "ele está certo em defender o melhor para ele"; "mas por que não fazem a prova de revalidação do diploma"; ou ainda "isso é populismo, só vai piorar a situação brasileira"... 
linguísticos, mas inscritos em uma ordem sócio-histórica e determinados a partir de um lugar social, que acabam sendo simbolizados pela língua. Para Pêcheux (1997, p.175), “esse vínculo entre as duas representações procede da identificação simbólica e, como tal, é representada através das leis da língua (lógica e gramática)".

Para o autor, é a partir da base linguística que construímos nossos discursos/processos discursivos, e portanto, utilizar a língua nas práticas sociais não é apenas uma questão estrutural, mas também quando produzimos nossos enunciados, entram em jogo elementos de outras ordens, como: ideológicos, sociais, históricos, simbólicos e políticos. Nesta perspectiva, é preciso admitir espaço para a indeterminação, falha, equívoco, esquecimento e perceber que o sentido da língua está preso à representação e a construções imaginárias, conforme as formações sociais e formações imaginárias, a partir dos quais os sujeitos se reconhecem. Isso significa que os efeitos de sentido das palavras são constituídos nas práticas sociais a partir do lugar social que o sujeito enuncia e pelo qual ele se reconhece como sujeito e "esses lugares estão representados nos processos discursivos" (PÊCHEUX, 2010, p. 82, grifo do autor), o que determina a escolha de alguns saberes e não de outros. Deste modo, o sujeito é um sujeito social e histórico e nessas condições se reconhece como sujeito. Como postula Pêcheux (1997), os indivíduos tornam-se sujeitos a partir da sua submissão à língua. Isso porque quando aprendemos a falar determinada língua, nela estão presentes saberes e é a partir desses saberes que nos reconhecemos. Desse modo, é que nós nos submetemos à língua, assujeitamo-nos a ela e subjetivamo-nos a partir de determinados discursos, imbricados de saberes. É a partir dos saberes, os pré-construídos que correspondem ao sempre-já-aí da interpelação e que nos fornecem as evidências do sentido.

Deste modo, ao tratarmos da produção de sentidos em textos de alunos de engenharias, devemos considerar que a produção de sentidos à respeito da violência contra crianças já foi construída a partir dos lugares sociais que alguns dos sujeitos alunos de engenharias, envolvidos na constituição desse discurso, ocupam. Conforme Pêcheux, trata-se do "'sempre já-aí' da interpelação ideológica que fornece-impõe a 'realidade' e 'seu sentido' sob a forma da universalidade” (PÊCHEUX, 1997, p. 164), o que corresponde ao pré-construído do discurso. Esse sujeito, ao ser interpelado pela ideologia e afetado pelas relações de poder, sobretudo as institucionais, já está inscrito num determinado lugar social, produzindo determinados efeitos de sentido.

É desse modo, então, que acreditamos que a categorização "alunos de engenharias" possa ser aqui tratada. Mas o que isso tem a ver com o político?

\section{A condição do político}

O político está presente em todo discurso como uma forma de direcionamento das relações histórico-sociais e ideológicas que põem os sujeitos e os sentidos em litígio (Rancière). Isto é, os diferentes posicionamentos que os alunos assumem frente a uma discussão constituem-se de sua relação com a ideologia, e o trilhar dessa relação se faz a partir do político. Orlandi (2011, p. 53) traz Pêcheux para explicitar que o político, pensado discursivamente, não se encontra somente no discurso político, mas no discurso em geral, porque é nesse que se dá o "confronto do simbólico com o político". Orlandi diz que não há sujeito nem sentido que não seja dividido, não há forma de estar no discurso sem constituir-se em uma posição sujeito e, portanto, inscrever-se em uma ou outra formação discursiva que, por sua vez, é a projeção da ideologia no dizer. As relações de poder são simbolizadas e isso é o político. A análise do discurso, por sua vez, como diz Courtine (1982), trabalha com a textualização do político. 
E tal textualização se constitui, em nosso trabalho, a partir dos sentidos produzidos pelos alunos de engenharias. Entretanto, diferentemente das questões apontadas anteriormente, o tema que desencadeou as discussões em análise (abuso sexual de crianças) não parece permitir as dissonâncias até então vistas, pois desnuda uma realidade indefensável que une diferentes sujeitos (diferentes alunos) em um mesmo lado da trincheira: na guerra contra os abusos infantis, instauram-se vítimas e agressores, e não há quem ouse sair em defesa dos últimos.

Essa, por si só, poderia ser considerada uma posição conservadora, afinal, a defesa das crianças parece alinhar-se perfeitamente às posturas de defesa da família tradicional, do recrudescimento das leis e penas, da censura de determinados espaços e atitudes e etc. Todavia, não nos esqueçamos que os sujeitos e os sentidos são sempre partidos, inapelavelmente ligados a formações ideológicas que também constituem-se a partir da contradição e que, portanto, permanecem - sujeitos e sentidos - em constante embate ideológico.

Pêcheux, em seu texto "O mecanismo do (des)conhecimento ideológico" (1996, apud Zizek), ao discutir os Aparelhos Ideológicos de Estado, de Althusser, reforça que a ideologia não se reproduz sob a forma de um Zeitgeist (um espírito de época, uma mentalidade). É por isso que para ele, na luta ideológica, não há "posições de classe" que tenham existência abstrata e que sejam posteriormente aplicadas aos diferentes "objetos" ideológicos regionais das situações concretas, na Escola, na Família, etc. De fato, é aí que a ligação contraditória entre a reprodução e a transformação das relações de produção articula-se no nível ideológico, na medida em que não são os "objetos" ideológicos, tomados um a um, mas a própria divisão em regiões (Deus, Ética, Lei, Justiça, Família, Saber etc.) e as relações de desigualdade-subordinação entre essas regiões que constituem o que está em jogo na luta ideológica de classes.

Desse modo, o que está em jogo nem sempre representa uma visão clara e coerente sobre determinado assunto, pois o discurso não se estabelece sobre um plano reto e homogêneo, mas na tensão das regiões que atravessam esse assunto. Assim, se há subordinação a um discurso de defesa irrestrita da criança, também aparecem efeitos de sentido que se articulam contraditoriamente, reforçando o que Pêcheux disse acima. Vejamos nas sequências didáticas retiradas dos textos dos alunos.

\section{Condições de Produção}

Antes, porém, cabe explicitar as condições de produção dos textos dos alunos. Courtine (2006) afirma que o discurso é geralmente definido como um enunciado emitido sob condições ou produção definida. E a noção de condições de produção recobre, assim, as operações efetivas na extração de um corpus discursivo fora de um universo de discurso, garante a representatividade do corpus extraído como uma função dos objetivos da investigação e de uma estrutura particular ao corpus.

Desse modo, os textos produzidos pelos alunos compõem a atividade de escrita diagnóstica. Ela serve para compreender como é o domínio de escrita dos alunos, seu conhecimento sobre gêneros textuais e observação de suas práticas de interpretação textual. Nas primeiras aulas do semestre, foi-lhes apresentado um texto que, após lido, deveria servir de base para uma produção textual. Nos primeiro e segundo semestres ${ }^{4}$ de 2017 (já que a disciplina é semestral), foi trazido aos alunos o texto "Lei expõe crianças a abuso",

4 Foram trabalhados com 5 turmas, com 40 alunos na média, perfazendo um total de 400 textos nos dois semestres. Desses, 3 turmas são de engenharias, totalizando 240 textos analisados para esse trabalho. 
do jornalista e escritor Tomás Chiaverini. O texto, publicado no site da Agência Pública (uma agência de reportagem e jornalismo investigativo), em 24 de janeiro de 2017, trata da aplicação da Lei de Alienação Parental como justificativa para denúncias que mães separadas fazem de abuso sexual aos filhos cometido pelos pais das crianças. Com a missão de produzir reportagens de fôlego, os textos publicados no site normalmente levam meses para serem construídos e são bastante longos. A reportagem em questão tem 24 páginas. Entretanto, como o objetivo da atividade era suscitar um tema para a produção do texto diagnóstico, foi levado para sala de aula somente a parte inicial do texto, que se encontra nas 4 primeiras páginas. Feita a leitura desse trecho, parte-se, sem qualquer discussão sobre o texto, para a seguinte proposta: "Produza um texto discutindo a temática abordada por Chiaverini, enfocando seu (autor) ponto de vista e posicionando-se sobre a questão."

Reforçamos que o objetivo é diagnosticar: compreensão do texto, conhecimento sobre produção textual e escrita. Nesse sentido, a proposta bastante genérica e a ausência de discussão do texto são propositais. Esses pontos serão feitos na aula sequencial a essa atividade, em que se explicitam os objetivos da proposta: a primeira parte requer a compreensão das ideias centrais do texto, reconhecimento da temática e possibilidade de exposição do tema; a segunda parte pretende observar a interpretação do aluno frente aos operadores argumentativos (vocabulário, direcionamento dos argumentos e exemplos) usados pelo autor e, na última parte, verificar os modos de argumentação do aluno, se centrados em ideias subjetivas ou argumentos mais objetivos.

De uma forma geral, os alunos reconheceram a tipologia expositiva-argumentativa requerida, ignoraram a segunda parte da proposta e trouxeram suas opiniões (e não posicionamentos) na conclusão dos textos. E é justamente dessas conclusões opinativas que retiramos a maior parte das nossas sequências discursivas.

\section{Análises}

Paul Henry (1975, p. 94 - publicação na Langages), citado por Courtine (2009, p. 33), afirma que todo discurso concreto é duplamente determinado, de um lado, por formações ideológicas que remetem esse discurso a formações discursivas definidas, de outro, pela autonomia relativa da língua, mesmo sem determinar o que é domínio de uma ou de outra. Já Courtine afirma que se os processos discursivos constituem a fonte da produção dos efeitos de sentido no discurso, a língua, pensada como uma instância relativamente autônoma, é o lugar material onde se realizam os efeitos de sentido.

Sob uma tal perspectiva, os textos dos alunos nos permitem visualizar diferentes efeitos de sentido que, como dito anteriormente, remetem ao que estamos chamando de posições conservadoras, pois ora elas lançam mão de um discurso moralizante, baseado em opiniões subjetivas para classificar as ações de abuso, ora desqualificam o poder público, responsabilizando-o pelos casos em questão. Há ainda uma terceira posição, na qual aparece a naturalização da culpa da mulher na alienação dos filhos, e que coloca-se em consonância com a motivação de base para a criação da lei de alienação parental.

\section{Monstruosidade}

Um discurso conservador é marcado - aparentemente - pela ausência de conflitos. Ele se dá, muitas vezes, na defesa de um posicionamento que tem sua sustentação ou na tradição, ou na moral de cunho religioso, ou ainda nas pretensões universalistas de um 
determinado grupo. Esse conservadorismo ou impede as discussões - épocas de censura, por exemplo - ou baseia-se em uma lembrança nebulosa, metamorfoseada de época ideal ou glória, na qual os sujeitos - desmemoriados histórica e politicamente - apegam-se e sustentam. Um dos pontos de ancoragem desse discurso é o esvaziamento das discussões, que deixam o plano das ideias e dos argumentos, e centram-se em opiniões subjetivas e moralistas, desvinculadas de objetividade concreta. Para muitos sujeitos conservadores, essa é a única forma de argumentar: adjetiva-se uma situação, externaliza-se sentimentos e voilà, tem-se um ponto de vista expresso e finalizado.

E é isso que podemos observar em algumas sequências discursivas dos textos dos alunos:

SD 1 - "Assim como é imprescindível as provas concretas, ouvir os relatos das vítimas também pode determinar o resultado de toda a ocorrência e evitar que elas, necessariamente, tenham que conviver com atos repugnantes e asquerosos vindos de seus próprios pais, pessoas que deveriam oferecer amor e segurança aos filhos” (L. S.)

SD 2 - "Sobre a lei da alienação parental mencionada, sou extremamente contra. Veja bem, no caso de Igor foi prejudicial a ele, imaginem quantos anos esta criança sofrerá convivendo com tamanha brutalidade. Entre casos e casos há pais inocentes, mas sou da seguinte opinião: a palavra, sentimento e expressão da criança conta muito, mesmo que estes inocentes estejam coagidos, mas a expressão sentimental irá revelar onde é o ambiente mais adequado." (A. P.)

SD 3 - "Abuso de lei seria a palavra certa, para todos os casos de abuso com crianças praticado por seus próprios pais, ou será mesmo que podemos chamar de pais? Um ser humano que seria responsável por cuidar faz uma covardia e brutalidade dessa com um ser indefeso, ou melhor seu próprio filho.” (M. D.) - mulher

A argumentação, nessas 3 sequências, baseia-se em separar o mundo entre vítimas e agressores, exaltando as características que compõem cada um dos lados. Em um plano bicolor, a adjetivação centra a argumentação na comoção, tendo a comparação como seu ápice: não há mais nada a se dizer quando quem deveria amar faz sofrer. Sequer merece o nome de pai, uma vez que esse só pode ser destinado a quem ama e cuida. Não estamos afirmando o contrário, mas o que marcamos aqui é justamente a desnecessidade de justificação que esse discurso apresenta, afinal o que há para contestar? E isso se dá, inclusive, quando apresentam-se as exceções. $\mathrm{Na}$ SD 2, o autor informa que há pais inocentes, mas sequer precisa explicar, porque o mundo já está estratificado, ou se é vítima ou se é agressor, e caso o pai seja inocente, o agressor será o outro, a mãe, e portanto segue-se na mesma linha de raciocínio, porque alguém sempre vai ser repugnante, covarde e brutal.

As palavras "repugnante, covarde e brutal", próprios do universo moral, remetem à noção de um sujeito agressor, despido de valores. Aqui não podemos pensar essas palavras apenas a partir da perspectiva estruturalista de Saussure (2012, p. 41), como um código, "suscetível de uma definição autônoma" e sendo possível de um estudo sistematizado e decomponível. Antes, é necessário analisar essas palavras a partir dos efeitos de sentido que elas assumem nas práticas sociais e, ao mesmo tempo, o lugar social, ao qual elas remetem. Como postula Pêcheux (1997), a língua em seu funcionamento desvela saberes, que pertencem a determinados discursos, pelos quais os sujeitos se identificam e são interpelados. 
Lei ridícula

Na mesma linha argumentativa de acima, as sequências discursivas desse segundo tópico dividem o mundo em dois planos, contudo, elas inserem as leis, o governo e o poder público ao mesmo lado dos agressores. Aqui os políticos, que fazem as leis, trabalham em defesa dos agressores, facilitando-lhes a transgressão e a prática da violência.

SD 4 - "As leis no Brasil estão sempre em transformação. [...] A mais ridícula lei atualmente em processo de mudança foi discutida em uma publicação de Tomás Chiaverini. [...] Esses casos chegam a ser ridículos, porém do ponto de vista político nada se pode fazer, pois a mesma que nos defende, é a lei que defende criminosos, abusadores e bandidos." (G. M.)

SD 5 - "O que não se leva em consideração é que os políticos, na maioria não têm formação em psicologia, serviço social ou profissões correlatas para uma análise sucinta para elaboração de leis nestes casos." (J. S.)

SD 6 - "É uma pena que o Brasil, país que tanto gostamos, é regido por pessoas que aprovam esse tipo de lei, que prejudicam mães e crianças, praticamente entregando de bandeja para seu pai e abusador, cuja pessoa que devia proteger e amar seu filho.” (S. B.)

SD 7 - “[...] Logo, percebe-se a fragilidade do Brasil, que não dá o devido valor a acontecimentos tão sérios, como abusos sexuais de crianças, e nem à vítima e demais pessoas que sofreram e sofrerão com ela por causa da violência sexual.” (J. B.)

Esse discurso, que parece banalizado, uma vez que costuma ser lugar comum culpabilizar os governantes pelos problemas de um país, acentua um discurso de redução do poder estatal, pois esse não tem competência para as funções que desempenha. Se as SDs 6 e 7 apelam para o lado emocional, construindo uma relação subjetiva entre poder público e descaso com a violência, as SDs 4 e 5 explicitam que, do modo como se constituem as leis hoje, elas não distinguem os dois lados existentes - bons e maus. Não é à toa que, no desconhecimento do aluno, ele atribui a psicólogos e assistentes sociais o título de pessoas especializadas "na arte de fazer leis", pois são esses profissionais que melhor, na perspectiva do autor, conhecem as nuances de caráter do ser humano, lidam mais intimamente com as consequências dos maus, e poderão fazer leis que segreguem de fato quem deve ser segregado. Não é possível que haja uma lei universal, indiscriminada, que defenda a todos. Isso é o que se tem feito até o momento, e vejam o resultado. É por isso que, acreditamos, o ridículo diz mais do que uma adjetivação subjetiva, é marca de um discurso que, em seu conservadorismo, não quer mudar a sociedade, somente determinar exatamente quem fica de cada lado da linha social.

\section{Culpa da mãe vingativa}

Mas o que mais nos chamou a atenção nos textos analisados foi a naturalização da condição da mulher, em uma situação de separação, como a abandonada e, como consequência, vingativa, desestabilizada e manipuladora. O tema em questão era a utilização da lei de Alienação Parental em casos de denúncia de abuso sexual, e todos os textos saíram 
em defesa de uma maior investigação quando as duas ocorrências cruzavam-se. Todavia, nenhum dos textos apontou para a extinção da Lei de Alienação Parental. Porém, naqueles que justificaram a importância de sua existência, somente os textos dos alunos de engenharias apontaram a importância da lei em razão de mães que tentam atrapalhar a relação dos filhos com os pais.

A lei de Alienação Parental foi criada com o objetivo de impedir que, em casos de divórcio, um cônjuge sabote a relação do outro com os filhos. A lei ganhou destaque, no Brasil, ao ser retratada em uma telenovela, em 2013, na qual o pai da criança, inconformado com a separação, influenciava a filha do casal a acreditar que a mãe não a amava e a abandonaria, como fizera com ele. Quer dizer, nem o texto de Chiaverini, nem mesmo o tratamento da questão em um folhetim (que muitas vezes banaliza questões importantes) davam margem para credenciar todos os casos, reais, de alienação parental a mães, mas foi isso que alguns alunos, e alunas também, das engenharias fizeram.

SD 8 - "Bom como dito no texto é comum nos dias de hoje pais separados, com isso na maioria dos casos os filhos ficam com as mães. Porém com isso pode ocorrer a tal da alienação parental, onde a família da mãe ou a própria mãe pode “jogar o filho(a) contra o pai” inventando histórias sobre o pai ou algo do tipo que possa quebrar os laços entre pais e filhos. Para evitar isso foi instituída a Lei 12.318, de agosto de 2010, “Alienação Parental”. (D. V.)

SD 9 - “Após diversos casos de mães que entram na justiça com pedido da guarda dos filhos alegando que os respectivos pais haviam cometido diferentes tipos de abusos, foi criada a lei 12.318 visando proteger o acusado caso não existam provas concretas de agressão. [...] Sendo assim, essa lei deveria ser revisada para que os filhos não corram o risco de ficarem sob controle dos malfeitores. Em contrapartida a lei deve continuar existindo pois pode ser eficaz quando se trata de mães controladoras, ou até mesmo pais." (D. M.)

SD 10 - "Embora o autor não se posicione diretamente a respeito dos casos, ele argumenta através dos dados onde mostram alguns casos de injustiças, induzindo a revolta do leitor com a lei da alienação. Contudo não se deve considerar a lei como totalmente ruim, pois mesmo que não apresentada na notícia da revista Apública, sabe-se que há diversos casos em que mães colocam os filhos contra os pais após o divórcio.” (P. S.)

SD 11 - "Se pensarmos pelo lado humano, emocional neste caso é muito difícil entendermos como pode a lei dar suporte para que tamanha monstruosidade continue acontecendo, acredito que os casos de abuso sexual deveriam ser investigados mais a fundo para que não ocorressem situações onde a vítima é obrigada a viver com o abusador. E que essa lei fosse usada em outros momentos, quando realmente houvesse interesse da mãe em afastar o filho do pai por uma vingança ou por motivos banais." (P. P.)

Impressiona-nos que, na tentativa de fazer uma exposição mais abrangente da questão, os textos expliquem a lei a partir da conduta da mulher como quem difama o homem. Não há discussão sobre isso, pois é assim e pronto. Nem mesmo na SD 9, em que, no final, o aluno parece aperceber-se dessa relação e insere, quase como um caso excepcional, a possibilidade do homem também tentar sabotar a relação da mãe com os filhos, 
nem mesmo aí os efeitos de sentido invertem-se. Os homens são seres brutais, violentos, e quando cometem crimes serão aqueles sexuais; mas a fofoca, o mal dizer, a influência perniciosa, esses quem o faz é a mulher, e faz isso porque está machucada, porque quer vingar-se, porque é instável e controladora. Portanto, as palavras se inscrevem em uma ordem social e carregam consigo um julgamento de valor inerente ao universo de uma sociedade patriarcal e machista. Ademais, não se minimizam os crimes sexuais, esses são hediondos, monstruosos, e precisam ser punidos, entretanto, se as acusações não forem verdadeiras, há homens que sofrem por conta de mulheres mentirosas que precisam ser punidas. Às vezes, essa indignação com a posição de uma mulher - desequilibrada - que coloca em risco a conduta e a imagem de um homem de bem chega a, inclusive, relativizar as possíveis punições aos dois. Vejamos a SD 12:

SD 12 - "Em alguns casos temos a infantilidade de um dos genitores, que usam os filhos para atingirem o outro, aí sim esta deve ser punida, porque a criança não tem nada a ver com a irresponsabilidade dos seus pais. E nos casos em que realmente houve o abuso deveria ser feita uma melhor investigação, e a palavra da vítima mesmo que seja uma criança deve ser levada em conta." (P. S.)

O que esta aluna, sim aluna, afirma em seu texto é a expressão máxima do discurso conservador. Nele, o mundo é masculino, e portanto a mulher tem um lugar secundarizado e não pode tentar inverter essa lógica. Caso tente trapacear, deve ser punida, não pelo que fez com os filhos, mas por querer atingir o outro, o homem. Contudo, se houver um abuso (porque no texto trabalha-se com o realmente havido), ação do homem, deve-se investigar mais profundamente, a fim de proteger a criança. Os efeitos de sentido, aqui, altamente discriminatórios, são apresentados como uma descrição de uma situação natural que, como tal, deve ser empregada. A solução, ideal de conclusão incutido pelo modelo Enem, aparece como uma "revelação" da sociedade como ela é e como deve continuar sendo.

Ao nos debruçarmos sobre os textos dos alunos, percebemos que as palavras usadas nos textos assumem significados a partir das condições de produção de seus discursos, considerando que a sociedade patriarcal é quem dita as regras em relação à conduta dos homens e das mulheres. Como se, a priori, é natural o homem separar-se da sua mulher e filho(s) e constituir outra família e a mulher irredutivelmente não quer aceitá-lo e ela usa o seu filho para fins vingativos. Esse fato parece algo naturalizado e parte-se em defesa do homem injustiçado pela ex-mulher. Infelizmente, as crianças vítimas ficam em segundo plano. Nesta perspectiva, se olharmos para os textos pelo viés da teoria estruturalista de Saussure, nos deteremos apenas no âmbito normativo da língua e suas respectivas regras sem seus efeitos de sentido, o de discursos naturalizados pela sociedade patriarcal, como se a origem dos escritos dos textos estivesse nos próprios alunos, desconsiderando a exterioridade que também os constitui. Isso porque as diferenças sociais são percebidas no interior da língua.

\section{Considerações Finais}

Observamos, a partir de nossas análises, que os discursos produzidos nos textos dos alunos de engenharias, mesmo que a um primeiro momento não nos parecesse, apontam, mesmo em questões aparentemente tão unânimes, como a defesa das crianças em situações de violência, para efeitos de sentido conservadores que, em casos mais extremos, 
tentam manter o status quo, reforçando as divisas sociais e ideológicas perseguidas pelos seus defensores em outros aspectos sócio-discursivos. Deste modo, as análises das sequências discursivas mostram que não há um reconhecimento de questões veladas, antes há um discurso moralizante, apontando culpados e adjetivando a monstruosidade de tal ato, "atos repugnantes e asquerosos vindos de seus próprios pais, pessoas que deveriam oferecer amor e segurança aos seus filhos" (SD1). Não obstante, práticas de violência são justificadas pela ausência de medidas judiciais mais eficazes e, ao mesmo tempo, análises mais complexas são substituídas por descrédito e por banalização de discursos sobre a não punição dos agressores "pois a mesma lei que nos defende, é a lei que defende criminosos, abusadores e bandidos" (SD4). Além da refração de fatos por meio de perspectiva individualista e conservadora, as sequências discursivas também estão imbuídas da estratificação social de gênero. Nessa estratificação, a condição de mulher aparece em uma perspectiva patriarcal, como vingativa e manipuladora, "sabe-se que há diversos casos em que mães colocam os filhos contra os pais após o divórcio” (SD9). Aqui, a mulher não está preocupada com o bem estar do seu filho, apenas disposta a difamar o homem - que a abandonou - e, acima de tudo, disposta a vingar-se. Nesse cenário de disputa, a mulher torna-se a vilã e o homem, muitas vezes, é inocentado, pautado na crença da vingança. Sendo assim, os efeitos de sentido das sequências discursivas das produções textuais analisadas, dado a partir das condições de produção, apontam para discursos mais conservadores e moralizantes.

De acordo com Pêcheux (1997), as palavras traduzem as relações do sujeito com aquilo que o representa, seja da ordem do político, do simbólico elou do ideológico. Isso significa que é na e a partir da materialidade da língua, que efeitos de sentido e sujeitos se constituem em uma fronteira tênue entre o linguístico, o histórico e o ideológico. Neste viés, a língua inscrita em uma ordem sócio-política significa e é concebida como prática social e em que a exterioridade lhe constitui e, ao mesmo tempo, escoam discursos e saberes que interpelam esses sujeitos-alunos e com os quais eles se identificam, se reconhecem e discursivizam. Portanto, essas expressões adjetivadoras, presentes nos textos, significam para além da perspectiva estruturalista da língua, antes significam na exterioridade, nas e a partir das práticas sociais, porque a língua "não produz por si mesma significações" (HENRY, 1992, p. 92), apontando para discursos naturalizados sobre a mulher e, ao mesmo tempo, para a ausência e a culpa do Estado.

\section{Referências}

COURTINE, J. J. Análise do discurso político: o discurso comunista endereçado aos cristãos. São Carlos: Edufscar, 2009.

. Metamorfoses do discurso político: as derivas da fala pública. São Carlos:

Claraluz, 2006. Tradução de Nilton Milanez e Carlos Piovezani Filho.

HENRY, P. A ferramenta imperfeita: língua, sujeito e discurso. Campinas: Editora da Unicamp, 1992.

ORLANDI, E. P. Documentário: acontecimentos discursivo, memória e interpretação. In: ZANDWAIS, A.; ROMÃO, L. M. S. (Org.). Leituras do político. Porto Alegre: Editora da UFRGS, 2011.

. (Org.). Gestos de Leitura: da história no discurso. 2. ed. Campinas: Editora da Unicamp, 1997. 


\section{Conexão Letras}

PÊCHEUX, M. Análise Automática do Discurso (AAD-69). In: GADET, F.; HAK, T.

Or uma análise automática do Discurso: uma introdução à obra de Michel Pêcheux. 4. ed. Campinas: Editora da Unicamp, 2010.

. O mecanismo do (des)conhecimento ideológico. In: ZIZEK, S. (Org.) Um mapa da ideologia. Rio de Janeiro: Contraponto, 1996. Tradução de Vera Ribeiro.

. Semântica e Discurso: uma crítica à afirmação do óbvio. 3. ed. Campinas:

Editora da Unicamp, 1997. Tradução de Eni Pulcinelli Orlandi.

SAUSSURE, F. Curso de linguística geral. 34. ed. São Paulo: Cultrix, 2012.

Recebido em: 09/04/2018 Aceito em: 11/05/2018 